ORIGINAL RESEARCH PAPER

\title{
DEVELOPMENT AND CHARACTERIZATION OF ADDED VALUE APPETIZER BISCUITS BASED ON BLACK RICE FLOUR
}

\author{
CARMEN-ALINA BOLEA*, MIHAELA TURTURICĂ, ELENA ENACHI, CAMELIA \\ VIZIREANU, NICOLETA STĂNCIUC \\ Faculty of Food Science and Engineering, Dunarea de Jos University of Galati, 111 Domneasca \\ Street, 800201 Galați, Romania \\ *Corresponding author: carmen.bolea@ugal.ro
}

Received on 20 August 2021

Revised on 26 October 2021

\begin{abstract}
The main purpose of this study followed the development of a functional product, a variety of biscuits with black rice flour, oat bran, almonds, and chia seeds. This type of biscuits revealed a high fibers content, $9.11 \pm 0.5 \%$, a fact attributed to the raw ingredients used, so as it is possible to label this type of product as "Rich in fiber". Furthermore, the black rice flour biscuits presented also a high protein concentration $(23.25 \pm 1.04 \%)$. In addition to the high content of proteins and fibers, this type of black rice flour biscuits showed a high antioxidant activity of $77.01 \pm 0.80 \%$. In regards to the in vitro digestion, the complex matrix of the biscuits allowed the protection of the antioxidant compounds, anthocyanins especially, in the gastric juice, allowing their release in the intestinal juice. Due to their composition, this category of biscuits can address a wide range of consumers, here including people with gluten intolerance (celiac disease). The developed functional product offers various advantages among them being the increase of product market share for the food industry targeting the people with gluten intolerance, the expansion of the functional products' field, the potential for technological transfer, and the development of new products with endowment in the specialized profile units.
\end{abstract}

Keywords: black rice, antioxidant activity, functional product, gluten intolerance

\section{Introduction}

According to a notable number of medical studies, celiac disease affects around $1 \%$ of the world's population, but in reality, the number of people suffering from this disease is significantly higher mainly because of the absence of a clear diagnosis, the only alternative for these consumers being to eat gluten-free foods. Although

https://doi.org/10.35219/foodtechnology.2021.2.04 
choosing a gluten-free diet can lead to certain nutritional imbalances in time, replacing the gluten-containing foods from somebody's diet would eliminate the source of protein that induces the symptoms of celiac disease. From this fact derives the concept that it is very important to develop gluten-free products because these products can also be extremely nutritious and, at the same time, economical. To achieve this type of product, some aspects need to be considered such as: the removal of all possible gluten-containing ingredients, the selection of an alternative source of flour, the acceptability and the color of the product, the enhancement of the nutritional quality of the product, the products' safety and proper labeling. All of these characteristics may contribute to the development of healthy or gluten-free foods for people with celiac disease (Jnawali et al., 2016).

Biscuits are among the most popular bakery products widely chosen by consumers of all ages, this being mainly due to their nature, nutritional qualities but also due to the availability of different varieties at affordable costs. The vast majority of bakery products are usually used as a source for the incorporation of various ingredients with a high nutritional value. Dietary fiber plays an extremely important role in the human diet so that soluble fiber is known for its hypocholesterolemic effect, while insoluble fiber is known to reduce the risk of colon cancer. Moreover, the $\beta$-glucan reduces both the risk of colon cancer and the absorption of glucose from the digestive system (Sudha et al., 2007).

The rice bran, in addition to its high vitamin content, is also a good source of dietary fiber (Sudha et al., 2007). Both the non-skimmed and skimmed rice bran have been incorporated into many bakery products, such as multi-granular bread, donuts, pancakes, muffins, and waffle mixes (Sudha et al., 2007).

In terms of increasing and improving the nutritional value and functionality of biscuits, several attempts have been made by changing or adjusting their composition mainly as a result of the increase in demand for healthy, natural, and functional products. Such effects can often be achieved by increasing the percentage of raw ingredients represented by whole grains or different types of dietary fiber other than wheat in basic recipes, in an attempt to increase the content and quality of the proteins, the content of minerals (Hooda and Jood, 2005; Tyagi et al., 2007) or to increase the dietary fiber content and improve the prebiotic characteristics of the final product (Gallagher et al., 2003). Another very important aspect of the functionality of food is the antioxidant capacity. Many scientific studies indicate the primary role of food antioxidants in preventing various types of cancer and heart disease (Marnett, 2000). Phenolic compounds are also the most active dietary antioxidants (Sudha et al., 2007), so the consumption of foods rich in phenols can provide an important source of natural antioxidants for the body (Vitali D. et al., 2008).

The interest in foods, rich in dietary fiber and antioxidants, has grown in the recent decades, and the importance of these food constituents has led to the development of a large market rich in antioxidants and fiber products and ingredients. The intake of dietary phytochemicals such as polyphenols, carotenoids, tocopherols, and ascorbic acid have been linked to maintaining human health and protection against 
diseases such as neoplasm, cardiovascular disease, and many other degenerative diseases (Wang and Jiao, 2000). Recently, fruits, vegetables, and cereals have received much attention as sources of biologically active substances, due to their antioxidant, anticarcinogenic and antimutagenic properties (Dillard and German, 2000). Several data are available on the use of oat bran, wheat bran, rice bran, as important sources of dietary fiber in the making of bread and other bakery products (Sidhu et al., 1999).

The products obtained with cereals play an important role in ensuring the needs of consumers. The biscuits are generally small baked goods, made mainly of flour, sugar, and fat. The biscuits can be made in many shapes and sizes, and after baking, they can be covered in chocolate or to present a pleasantly flavored filling. Recently, Sudha et al. (2007) reported the influence of different grain brands on the sensory quality of biscuits (Ajila, et al., 2008).

Biscuits are food products with a long shelf-life, so that to obtain them involves the process of baking certain dough prepared with different ingredients such as: flour, sugar, water, and other additives with a high nutritional value. Biscuits have special properties in terms of taste and nutritional value, considering the nutritional value as an important element for the level of daily food ratio, and the subject of extensive research in the field of nutrition. The diversity of biscuits is due to the many raw and auxiliary ingredients used, the different proportions, and the technological processes applied, so that the given high content of fatty substances and carbohydrates of the biscuits.

Given the high content of fatty substances and carbohydrates, it is estimated that biscuits bring an important energy contribution. Black rice flour may represent an alternative source for developing gluten-free products, with certain advantages given by the presence of biologically active compounds. Molecules with antioxidant activity in black rice flour include phenolic acids, flavonoids, anthocyanins, proanthocyanidins, tocopherols, tocotrienols, $\gamma$-oryzanol, and phytic acid. Therefore, the main objective of this study was to develop gluten-free appetizer biscuits based on black rice flour as an alternative to white rice flourbased ones. The obtained biscuits were characterized from physico-chemical and microbiological points of view, and stability over 21 days of storage were tested.

\section{Materials and methods}

\section{Materials}

The raw materials used to obtain the appetizer biscuits, namely black rice, white rice, oat bran, chia seeds, almonds, salt, and baking powder were purchased from a local supermarket in Galați, in 2019. Both types of rice were products from Scotti Gourmet.

The black and white rice flours were obtained by fine grinding the black rice grains in a laboratory mill (Mlynek Laboratory JNY Type WZ / 2). The flours were the main ingredient used to obtain the biscuits and it was chosen due to the fact that the 
black rice flour has in its composition a series of biologically active compounds (anthocyanins, phenols, flavonoids) and does not contain gluten.

\section{Formula for biscuits}

In order to obtain the value-added product, the dough was prepared by mixing all the ingredients, namely $30 \mathrm{~g}$ of black rice flour, $65 \mathrm{~g}$ of oat bran, $5 \mathrm{~g}$ of chia seeds, $10 \mathrm{~g}$ of almonds, $2.5 \mathrm{~g}$ salt, baking powder $0.5 \mathrm{~g}$, oil $5 \mathrm{~mL}$, thyme $2 \mathrm{~g}$, pepper $1 \mathrm{~g}$, rosemary $1 \mathrm{~g}$ and warm water $\left(40^{\circ} \mathrm{C}\right) 60 \mathrm{~mL}$, these values corresponding to one hundred grams of appetizer biscuits. The control samples consisted of similar products prepared with white rice flour instead of black rice flour. The appetizer biscuits with black rice flour were coded BRB, and those with white rice flour, WRB. Both types of biscuits were baked at $180^{\circ} \mathrm{C}$, for 20 minutes.

\section{Analysis of proximal composition of biscuits}

The composition of the obtained appetizer biscuits was determined using the following methods: moisture content using the AOAC method (1990), proteins by the Kjeldahl method (AACC method 46-13), lipids by Soxhlet extraction, ash content by the SR ISO 2171:2002 method (ASRO, 2008), and crude fibers using the official AOAC method 962.09. The carbohydrate content was estimated by subtracting the proteins, ash, lipids, and fiber from the dry weight of the samples.

\section{Extraction of polyphenolic compounds}

The biscuits $(1 \mathrm{~g})$ were homogenized with $8 \mathrm{~mL}$ ethanol (70\%) and stirred using an orbital shaker at room temperature for 24 hours to extract the polyphenolic compounds. The extract thus obtained was centrifuged at a speed of $5000 \mathrm{xg}$ for 30 minutes. The final samples were stored at $4^{\circ} \mathrm{C}$ for further characterization.

\section{Phytochemical analyses}

The ethanolic extracts of biscuits were characterized in terms of total monomeric anthocyanin content (TAC), total polyphenolic (TPC), and total flavonoids content (TFC) antioxidant activity, expressed as 2,2-diphenyl-1-picrylylhydrazyl (DPPHRSA) radical scavenging activity, as described by Bolea et al. (2016).

\section{In vitro digestion of appetizer biscuits}

To simulate the digestion, the crushed biscuits were first mixed with a Tris-HCl buffer $(10 \mathrm{mM}, \mathrm{pH} 7.7)$, using a ratio of $1 \mathrm{~g}$ product/10 $\mathrm{mL}$ buffer solution. The simulated gastric fluid (SGF) containing porcine pepsin $(20 \mathrm{mg})$ and $0.1 \mathrm{~N} \mathrm{HCl}(20$ $\mathrm{mL}$ ) at $\mathrm{pH} 2.0$ was added to simulate the stomach conditions. The incubation was performed at $37^{\circ} \mathrm{C}$ using an incubator that allowed the orbital agitation (Optic Ivymen System) at 150 RPM. The anthocyanins content was quantified every 30 minutes over 120 minutes of in vitro digestion simulation, according to the method described by Oancea et al. (2017).

In order to check the effect of further enteric digestion, the simulated intestinal fluid (SIF) was prepared as a mixture containing pancreatin $(40 \mathrm{mg}$ ) and sodium bicarbonate $0.9 \mathrm{M}(20 \mathrm{~mL})$. The $\mathrm{pH}$ of the mixture was finally adjusted to $\mathrm{pH}$ 7.7. The enteric digestion was simulated using the SIF juice, which was allowed to act on the mixture resulting from the gastric hydrolysis. 


\section{Sensory analysis}

The sensory analysis of the biscuits was performed by eleven students of the Faculty of Food Science and Engineering, "Dunarea de Jos" University of Galati, Romania who were previously trained. The sensory analysis was assessed in a bright, well-ventilated space, at a temperature between $22-24^{\circ} \mathrm{C}$ and at a relative humidity between $45-47 \%$. The thickness of the biscuits subjected to the sensory analysis was $4-5 \mathrm{~mm}$. To assess the sensory characteristics, a scale of 0 to 5 was used. Each student received an analysis bulletin and a document containing the definitions of the appreciated sensory attributes, such as: smell, taste, flavor, aftertaste, mouthfeel, appearance, and appearance in section (form, thickness, degree of maturation, pore size).

\section{Determination of immunological markers using the ELISA method}

The presence of gluten in the composition of the black rice flour based biscuits was assessed using the ELISA technique (Enzyme-linked immunosorbent assay). The tests were performed using the commercially available RIDASCREEN® Gliadin kits that allow the quantitative analysis of gliadin), secaline and hordein in glutenfree foods. All the reagents used for the enzyme immunoassay - including the standards were contained in the test kit.

The samples were prepared according to the specifications given by the manufacturer (Biopharm AG, Darmstadt, Germany). The detection of the potentially allergenic proteins by the ELISA sandwich technique involved firstly the binding of the allergen to a specific antibody that is immobilized in the microplate wells, followed by its detection by a second specific peroxidaseconjugated antibody. Finally, the substrate was converted by the conjugated enzyme, the reaction being stopped with $\mathrm{H}_{2} \mathrm{SO}_{4} 1 \mathrm{~N}$. The absorbance of the samples was measured at $450 \mathrm{~nm}$ wavelength using a microplate reader spectrophotometer (Stat Fax 4200, Awareness Technology, USA). The absorbance is proportional to the concentration of gliadin in the sample.

\section{Colorimetric determination}

The color of the biscuits was determined using the CHROMA METER CR-410 colorimeter that allowed the determination of the $\mathrm{L} *, \mathrm{a} *$, and $\mathrm{b} *(\mathrm{~L} *$-luminosity, $\mathrm{a} *$-yellow/blue spectrum, $\mathrm{b} *$-red/green spectrum) parameters.

\section{Microbiological determinations}

The microbiological analysis was performed in the laboratory of the physicochemical and microbiological analysis of food (LAFCMA) of the Faculty of Food Science and Engineering, "Dunarea de Jos" University of Galati, Romania according to the SR ISO 21527/1 standard. To determine the number of yeasts and molds, 10 grams of each sample were taken and transferred aseptically into sterile bags over which $90 \mathrm{~mL}$ of sterile distilled water were added. The samples were then stirred for 2 minutes with the Bagmixer homogenizer and decimal dilutions were made for the inoculation. After the incubation for 7 days at $25^{\circ} \mathrm{C}$, the formed colonies were counted and the results were expressed as CFU/g sample. 


\section{Statistical analysis}

The determinations were performed in triplicate so that all results are presented as mean values (SD) together with standard deviation. Therefore, the unique damage analysis (ANOVA) and the Tukey test with a confidence interval of $90 \%$ were applied, using the Minitab software version 18 in order to be able to identify the significant differences.

\section{Results and discussion}

\section{Physico-chemical characterization of biscuits}

The results of the physico-chemical analysis performed on the functional product intended for people with food intolerances (biscuits) are presented in Table 1.

Table 1. The physico-chemical composition of the biscuits.

\begin{tabular}{lcc}
\hline \multicolumn{1}{c}{ Parameters } & $\begin{array}{c}\text { BRB (black rice } \\
\text { biscuits) }\end{array}$ & $\begin{array}{c}\text { WRB (white rice } \\
\text { biscuits) }\end{array}$ \\
\hline Ash \% & $5.98 \pm 0.12^{\mathrm{a}}$ & $3.7 \pm 0.32^{\mathrm{b}}$ \\
Lipids \% & $15.71 \pm 0.69^{\mathrm{a}}$ & $15.03 \pm 0.01^{\mathrm{a}}$ \\
Proteins \% & $23.25 \pm 0.15^{\mathrm{a}}$ & $19.36 \pm 0.76^{\mathrm{b}}$ \\
Moisture \% & $3.42 \pm 0,68^{\mathrm{a}}$ & $1.02 \pm 0.06^{\mathrm{b}}$ \\
Fibers \% & $9.11 \pm 0.40^{\mathrm{a}}$ & $8.06 \pm 0.22^{\mathrm{b}}$ \\
\hline
\end{tabular}

On each row means that do not share the same letter $(a, b)$ are statistically different at $p<0.01$ based on the Tukey test.

According to the results shown in Table 1, it can be seen that the biscuits obtained at the laboratory level, using black rice flour as the main ingredient, presented high content of proteins and fibers $(23.25 \pm 1.04 \%$ and $9.11 \pm 0.5 \%$, respectively). Given the high fiber content of the biscuits and due to the raw ingredients, that were used to obtain them, it is possible to label the obtained product as "Rich in fiber". Compared to other foods, black rice is rich in protein, iron, vegetable fats, vitamins, and minerals, but especially in fiber, thus leading to a balance of the human body (Sangma and Parameshwari, 2021). Wesley et al. (2021) prepared gluten-free biscuits using white beans flour and brown rice flour as primary ingredients, and they reported a fiber content of $6.30 \pm 1.01 \mathrm{mg} / 100 \mathrm{~g}$. For the cupcakes prepared with the high protein brown rice flour, Aleman et al. (2021) reported protein content of $12.21 \pm 0.14 \mathrm{~g} / 100 \mathrm{~g}$. Also, the cupcakes obtained from brown rice flour recorded ash, moisture, and lipid content values of $1.83 \pm 0.26$ $\mathrm{g} / 100 \mathrm{~g}, 11.05 \pm 0.54 \mathrm{~g} / 100 \mathrm{~g}$, and $1.39 \pm 0.22 \mathrm{~g} / 100 \mathrm{~g}$, respectively. The study of Indriani et al., (2019) on products based on brown rice flour showed the protein content of $11.47 \pm 0.10 \%$, the lipid content of $1.81 \pm 0.16 \%$, the fiber content of $1.59 \pm 0.07 \%$ whereas for the moisture and ash content, $12.85 \pm 0.06 \%$ and $1.47 \pm$ 0.01 , respectively. 
Another study by Mir et al. (2017) investigated the content of proteins, lipids, and fibers in two brown rice flour crackers, K-332 variety and Khosar variety, without the addition of apple pomace powder that displayed rather similar values. For the $\mathrm{K}-332$ brown rice flour variety, the protein content was $7.10 \pm 0.48 \mathrm{~g} / 100 \mathrm{~g}$, the lipid content was $17.33 \pm 0.36 \mathrm{~g} / 100 \mathrm{~g}$, and the fiber content was $3.10 \pm 0.05 \mathrm{~g} /$ $100 \mathrm{~g}$. In the second type of crackers with the Khosar variety of brown rice flour, the protein content registered a value of $7.67 \pm 0.31 \mathrm{~g} / 100 \mathrm{~g}$, lipids of $17.46 \pm 0.22$ $\mathrm{g} / 100 \mathrm{~g}$, and fibers of $3.01 \pm 0.09 \mathrm{~g} / 100 \mathrm{~g}$.

\section{Phytochemical profile of appetizer biscuits and stability storage}

The initial content of the biologically active compounds was evaluated in the dough for the biscuits, before the baking operation. The obtained dough showed the following content of biologically active compounds: TAC $65.01 \pm 1.2 \mathrm{mg} \mathrm{C} 3 \mathrm{G} / 100$ $\mathrm{g}$; TPC $322.1 \pm 2.01 \mathrm{mg} \mathrm{CA} / 100 \mathrm{~g}$; TFC $287 \pm 3.03 \mathrm{mg} \mathrm{CE} / 100 \mathrm{~g} ; 87.96 \pm 0.71 \%$ DPPH RSA for BRB. The biologically active compounds from the WRB dough before the baking recorded the following values: $22.45 \pm 1.02 \mathrm{mg} \mathrm{C} 3 \mathrm{G} / 100 \mathrm{~g}$ for the total anthocyanin content, $30.21 \pm 0.31 \mathrm{mg}$ GA/100 $\mathrm{g}$ for the total polyphenols content, $28.74 \pm 0.11 \mathrm{mg} \mathrm{CE} / 100 \mathrm{~g}$ for total flavonoids and an antioxidant activity of $68.87 \pm 1.41 \%$ DPPH RSA. After the baking process, the content of these compounds and the antioxidant activity decreased so that the anthocyanin content reached $17.53 \pm 0.00 \mathrm{mg} \mathrm{C} 3 \mathrm{G} / 100 \mathrm{~g}$, a polyphenols content of $24.85 \pm 0.32 \mathrm{mg}$ $\mathrm{GA} / 100 \mathrm{~g}$, a flavonoid content of $22.68 \pm 0.21 \mathrm{mg}$ CE/100 g while antioxidant activity recorded a value of $66.91 \pm 0.47 \%$ DPPH RSA.

On the other hand, the BRB type displayed after the baking process a significant amount of biologically active compounds (TAC $50 \mathrm{mg} \mathrm{C} 3 \mathrm{G} / 100 \mathrm{~g}$, TPC $162.21 \pm 0.39 \mathrm{mg}$ GA $/ 100 \mathrm{~g}$, TFC $151.05 \pm 0.18 \mathrm{mg}$ CE/100g, $71 \pm 0.20 \% \mathrm{DPPH}$ RSA). During a 21-days storage period $\left(20^{\circ} \mathrm{C}, 50-60 \%\right.$ relative humidity), an increase of the total anthocyanins content (TAC), the total polyphenols content (TPC), the flavonoids content (TFC), and the antioxidant activity (DPPH RSA) was observed in the case of the black rice flour appetizer biscuits, recording values significantly higher compared to the white rice flour biscuits (Table 2).

Table 2. The evolution of the biologically active compounds content during storage at room temperature for the appetizer biscuits BRB.

\begin{tabular}{crrrr}
\hline $\begin{array}{c}\text { Biologically active } \\
\text { compounds }\end{array}$ & \multicolumn{5}{c}{ Storage period, days } \\
\hline TAC, mg C $\mathbf{3} / \mathbf{1 0 0}$ g & $50.00 \pm 1.01^{\mathrm{a}}$ & $24.27 \pm 0.33^{\mathrm{b}}$ & $24.20 \pm 0.27^{\mathrm{b}}$ & $24.00 \pm 0.01^{\mathrm{b}}$ \\
TPC, $\mathbf{m g ~ G A} / \mathbf{1 0 0} \mathbf{g}$ & $162.21 \pm 0.39^{\mathrm{d}}$ & $166.35 \pm 0.47^{\mathrm{b}}$ & $177.10 \pm 0.18^{\mathrm{c}}$ & $188.00 \pm 0.20^{\mathrm{a}}$ \\
TFC, mg CE/100 g & $151.05 \pm 0.18^{\mathrm{c}}$ & $158.11 \pm 0.32^{\mathrm{b}}$ & $158.85 \pm 0.08^{\mathrm{b}}$ & $164.15 \pm 0.55^{\mathrm{a}}$ \\
DPPH RSA, \% & $71.00 \pm 0.20^{\mathrm{c}}$ & $74.32 \pm 0.44^{\mathrm{b}}$ & $76.94 \pm 0.97^{\mathrm{a}}$ & $77.01 \pm 0.50^{\mathrm{a}}$ \\
\hline
\end{tabular}

On each row means that do not share the same letter $(a, b, c, d)$ are statistically different at $p<0.01$ based on the Tukey test. 
Analyzing the results presented in Table 2 it can be seen that the biscuits recorded a decrease of the total anthocyanins content in the first 7 days of storage, afterwards the value remained constant for up to 21 days $\left(24 \pm 0.01 \mathrm{mg} \mathrm{C}_{3} \mathrm{G} / 100\right.$ $\mathrm{g}$ ), while the total content of polyphenols and flavonoids increased slightly throughout the period considered in the study. Polyphenols, as biologically active molecules, undergo different processes in the food matrices so that these compounds' structure can be affected by their interaction with other food constituents. As an example, the co-pigmentation process of anthocyanins takes place mainly because these compounds interact with several other molecules from the matrix which in term results in color intensification (Cao et al., 2021).

The evolution of the antioxidant activity followed the same trend as the one observed in the case of the polyphenols and flavonoids contents. It can, thus, be appreciated that the concentration of the total polyphenols and flavonoids mainly influenced the antioxidant activity values of the biscuits.

Das et al. (2019) demonstrated that after the baking process at $160^{\circ} \mathrm{C}$, the red rice cake presented a content of total anthocyanins of $0.9 \pm 0.1 \mathrm{mg} \mathrm{C} 3 \mathrm{G} / 100 \mathrm{~g}$, the value that decreased significantly compared to the value of the native cake $(6.9 \pm$ $0.1 \mathrm{mg} \mathrm{C} 3 \mathrm{G} / 100 \mathrm{~g}$ ). Furthermore, after the baking process, the content of the total polyphenols and the antioxidant activity of the red rice flour cake was $17.9 \pm 2.4$ $\mathrm{mg} \mathrm{GA} / 100 \mathrm{~g}$ and $5.9 \pm 1.5 \% \mathrm{DPPH}$, respectively, the initial values being $199.4 \pm$ $0.2 \mathrm{mg} \mathrm{GA} / 100 \mathrm{~g}$ for TPC and $54.5 \pm 0.4 \%$ for DPPH (Das et al., 2019).

The content of polyphenols, flavonoids, and also the antioxidant activity of the two types of crackers obtained from the K-332 and Khosar brown rice flour varieties, without the addition of apple pomace powder, recorded values of $0.61 \pm 0.03 \mathrm{mg}$ $\mathrm{GAE} / \mathrm{g}, 55.49 \pm 1.13 \mu \mathrm{g}$ catechin equivalent $/ \mathrm{g}, 51.70 \pm 1.94 \% \mathrm{DPPH}$ for the K332 variety and values of $0.58 \pm 0.01 \mathrm{mg} \mathrm{GAE} / \mathrm{g}, 41.96 \pm 1.27 \mu \mathrm{g}$ catechin equivalent / g, $47.80 \pm 2.48 \%$ DPPH in the case of crackers with the Khosar variety (Mir et al., 2017).

\section{In vitro digestibility of appetizer biscuits}

The digestion of the biologically active compounds in the gastrointestinal tract is a complex process, with a major impact on their release, distribution, and bioavailability (Sari et al., 2015). In the present study, the kinetics of the release of anthocyanin compounds from the biscuits during the in vitro digestion was followed (Figure 1). In the simulated gastric juice, a decrease of the total monomeric anthocyanins' content was observed, with about $34 \%$ in the first 30 minutes of digestion and about $44 \%$ after 120 minutes. In the simulated intestinal juice, an increase of the anthocyanin compounds' release was observed (Figure 1), around 3 times after 30 minutes of the intestinal digestion and around 5 times after 120 minutes. Thus, it can be stated that the complex matrix of the biscuits allowed the protection of the anthocyanin compounds in the gastric juice, allowing their release in the intestinal juice. The release of the anthocyanins during the simulation of the gastric digestion suggested that the proteins protect the anthocyanins, thus allowing a controlled release of the bioactive compounds under the influence of the gastric and intestinal enzymes from the simulated juices. 


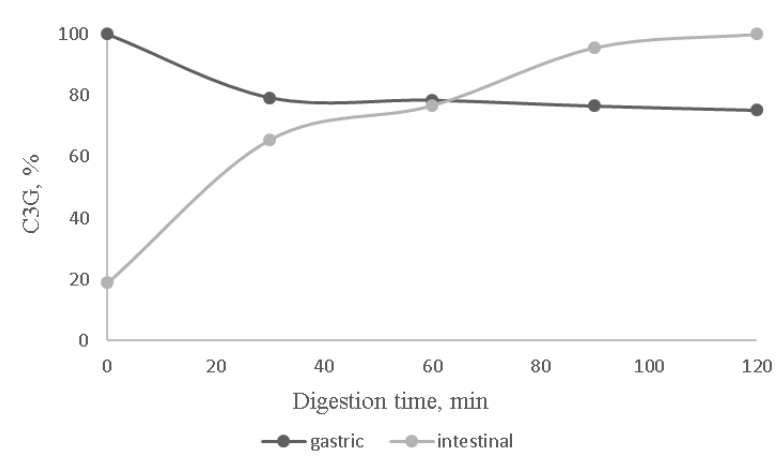

Figure 1. The anthocyanin content during the simulated gastric and intestinal digestion of the black rice flour biscuits (BRB).

The stability of anthocyanins is directly influenced by the $\mathrm{pH}$, these types of compounds being stable at an acidic value and unstable at an alkaline value. Fang (2014) suggested that anthocyanins are metabolized to anthocyanidin by removing the sugars in the intestine, followed by their transformation into smaller compounds such as protochatehuic acid and ferulic acid. According to Stevens and Maier (2016), the metabolism of anthocyanins takes place in alkaline conditions of the intestinal environment by opening the intramolecular heterocyclic yellowish ring. Kim et al. (2020) suggested that during the gastric digestion of a mulberry extract, the levels of cyanidin-3-O-glucoside and pelargonidin-3-O-glucoside decreased by $84 \%$ and $46 \%$, with an increase of the aglycone forms, respectively.

\section{Testing the antigenic potential of the biscuits}

The ELISA test that regards the R5 monoclonal antibody, as suggested by Codex Alimentarius (2005) for food analysis, was used to quantify the antigenic properties of the gliadins that may possibly be present in the black rice flour biscuits. Following the ELISA analysis, the obtained value was below the allowable limit of $20 \mathrm{mg}$ gluten $/ \mathrm{kg}$, which indicated in terms of the absence of the potentially allergenic proteins in the biscuits. According to the ELISA analysis, the appetizer biscuits can be successfully classified into the category of aglutenic products.

\section{Colorimetric characteristics of the obtained biscuits}

The values of the $L^{*} a^{*} b^{*}$ color indices measured using the HunterLab Miniscan XE Plus instrument are presented in Table 3. The $\mathrm{L}^{*} \mathrm{a}^{*} \mathrm{~b}^{*}$ CIE parameters in the rectangular system are: L - brightness coordinate: 0 (black) up to 100 (white); $\mathrm{a}^{*}$ $\mathrm{red} /$ green coordinate, with $+\mathrm{a}^{*}$ indicating red and $-\mathrm{a}^{*}$ indicating green; $\mathrm{b}^{*}$ yellow/blue coordinate, with $+b^{*}$ indicating yellow and $-b^{*}$ indicating blue. The values of the colorimetric indices $\mathrm{a}^{*}$ and $\mathrm{b}^{*}$ indicated that the biscuits presented a color with stable shades of red-orange and yellow, the intensity of which gradually decreased during storage. The brightness $\left(\mathrm{L}^{*}\right)$ remained constant throughout the whole storage period.

Following the determination of the color indices in the case of the control sample biscuits, the recorded value of the $\mathrm{L}^{*}$ index was $34.94 \pm 1.74$, an $\mathrm{a}^{*}$ index of 
$5.82 \pm 0.25$ and $a b^{*}$ index of $15.59 \pm 0.22$. Compared to the BRB sample, the WRB revealed lower color index values mainly due to the high content of polyphenolic compounds from the black rice flour.

Table 3. Colorimetric indicators of the BRB.

\begin{tabular}{lcccc}
\hline \multicolumn{1}{c}{ Indices } & Initial & After 7 days & After 14 days & After 21 days \\
\hline $\mathrm{L}^{*}$ & $39.14 \pm 0.55^{\mathrm{a}}$ & $39.20 \pm 0.56^{\mathrm{a}}$ & $39.24 \pm 0.5^{\mathrm{a}}$ & $39.26 \pm 0.64^{\mathrm{a}}$ \\
$\mathrm{a}^{*}$ & $7.63 \pm 0.72^{\mathrm{a}}$ & $7.41 \pm 1.04^{\mathrm{a}}$ & $7.14 \pm 0.14^{\mathrm{a}}$ & $7.05 \pm 0.50^{\mathrm{a}}$ \\
$\mathrm{b}^{*}$ & $14.26 \pm 0.64^{\mathrm{a}}$ & $13.04 \pm 0.44^{\mathrm{a}}$ & $11.23 \pm 0.5^{\mathrm{b}}$ & $9.52 \pm 0.58^{\mathrm{c}}$ \\
\hline
\end{tabular}

On each row means that do not share the same letter $(a, b)$ are statistically different at $p<0.01$ based on the Tukey test.

It can be seen that the values of the colorimetric indices $\mathrm{L} *$ and a $*$ do not have a significant variation during the 21 days, which means that the biscuits retain their color throughout the shelf life. Instead, it can be seen that the $\mathrm{b} *$ chromaticity coordinate shows a decrease in the variation over the 21 days, which means that the appetizer biscuits are found in the yellow color spectrum, being influenced by the high polyphenolic and flavonoid content. According to the study conducted by Aleman et al. (2021), the cupcakes obtained in the proportion of 80:20:0 (brown rice flour: tapioca starch: corn starch) displayed different values of the color indices, respectively of $66.53 \pm 0.04$ for the $\mathrm{L}^{*}$ index, $7.53 \pm 0.01$ for the $\mathrm{a}^{*}$ index and $25.40 \pm 0.01$ for the $b^{*}$ index. In 2019 , Indiani et al. (2019) highlighted L*, $a^{*}$ and $b^{*}$ color index values of $88.29 \pm 0.14,0.87 \pm 0.02$ and $12.44 \pm 0.14$ for the brown rice flour control cakes.

According to the study conducted by Das et al. (2019), the color parameters determined for a red rice cake product registered values of $13.95 \pm 2.91$ in the case of $\mathrm{L}^{*}, 12.11 \pm 0.94$ for the $\mathrm{a}^{*}$ parameter and a value of $9.28 \pm 1.92$ for the $\mathrm{b}^{*}$ index of color after the baking process at $60^{\circ} \mathrm{C}$, for 30 minutes.

The color parameters of the K-332 brown rice flour variety crackers obtained by Mir et al. (2017), without the addition of apple pomace powder, displayed different values for the color parameters, respectively $53.63 \pm 0.76$ for the $L^{*}$ index, $10.05 \pm$ 0.19 for the $\mathrm{a}^{*}$ index and $27.32 \pm 0.16$ for the $\mathrm{b}^{*}$ index. At the same time, for the Khosar brown rice flour variety crackers without the addition of apple powder, the color index values were $56.09 \pm 0.11$ for $L^{*}, 10.21 \pm 0.14$ for $a^{*}$ and $28.18 \pm 0.18$ for $b^{*}$.

\section{Microbiological analysis}

The analysis of the total number of yeasts and molds demonstrated that the two aglutenic biscuits were microbiologically satisfactory throughout the whole studied period of 21 days. Based on these results, it could be appreciated that the conditions used for the baking process were appropriate causing the destruction of yeasts and molds so that the functional product for people with food intolerances is safe for consumption. 
According to the results obtained from microbiological analyzes, it was found that after the 7, 14, and 21 days of storage the total number of yeasts and molds was less than $10 \mathrm{CFU} / \mathrm{g}$ in both BRB and WRB samples.

\section{Sensory analysis}

The decision to accept or reject a certain food product is based mainly on its sensory qualities that have a very important role, influencing the consumer's reaction to that type of food product. The quality of a product represents the total characteristics able to satisfy the needs of the consumers. Sensory analysis is a part of the concept of quality and represents the method to examine a product using the most basic human senses such as hearing, sight, taste, and smell. To characterize the aroma and taste of a product a very specific sensory analysis must be undertaken. The methods of a sensory analysis can be objective or subjective. The subjective method is the hedonic analysis or preference test that measures the appreciation of a product by "non- trained" consumers, while the objective method is the sensory analysis performed in the laboratory by a group of trained experts. The basic competencies of a sensory analysis expert are repeatability (from a series of samples, the identification of the identical ones) and discrimination (the ability to distinguish one sample from another) (Segal and Barbu, 1982).

Regarding the sensory profile of the BRB and WRB, it can be seen from Figure 2, that during the tasting, the smell, flavor, taste, aftertaste, and mouthfeel were perceived by the panelists to a greater extent, thus giving these characteristics a high score for BRB. On the other hand, for the WRB, the panelists considered that this type of biscuits presented a lower score in terms of quality compared to those made of black rice. The mouthfeel perceived by the panelists registered a lower score compared to the other sensory characteristics.

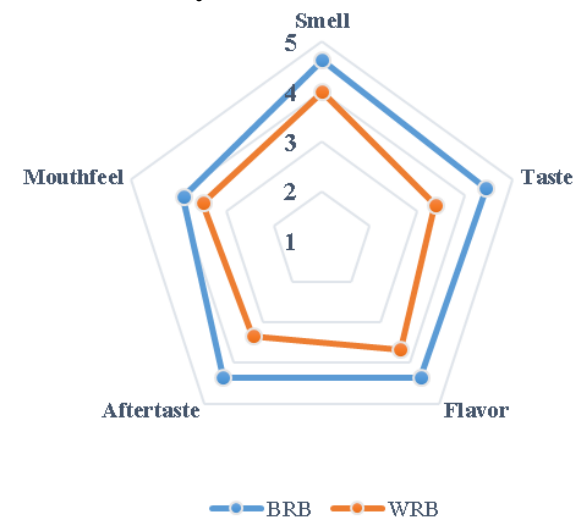

Figure 2. The sensory profile of the functional product for people with food intolerances.

Following the sensory analysis carried out by Aleman et al. (2021) on the brown rice flour, tapioca starch, and corn starch cupcakes in a ratio of 80:20: 0 , the scores obtained in terms of attributes such as aroma, texture, and flavor were 5.77, 6.24 and 6.21 respectively. 
The sensory properties of the protein-enriched brown rice cupcakes indicated a score of 7.6 for flavor, a score of 7.7 for taste, 7.5 for texture, 8.3 for appearance, and a score of 7.4 for aftertaste (Indriani et al., 2019).

According to the results presented in Figure 3, it was observed that the appearance in section, resulting from the breaking of the biscuits in two, presented a high score similar to the one obtained for the thickness characteristic. Nonetheless, the other sensory attributes had lower scores given by the panelists because the biscuits did not present a smooth surface, being very thin and crunchy.

Based on the results of the sensory analysis, it could be appreciated that the biscuits were highly appreciated by the panelists, especially due to their taste and satiety level.

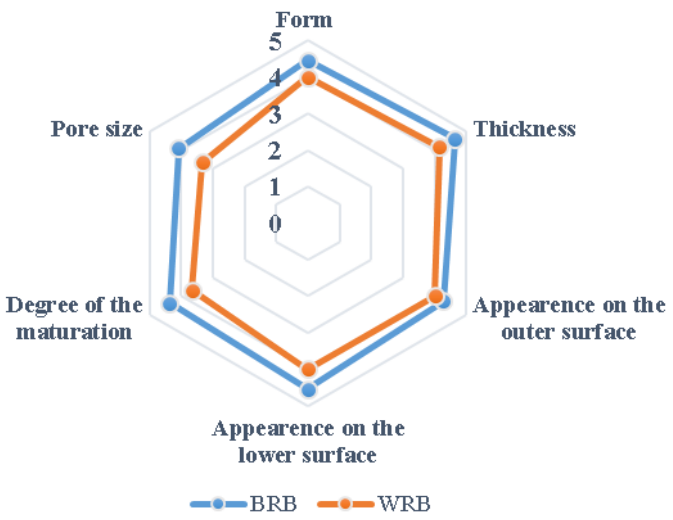

Figure 3. The sensory profile of the functional product for people with food intolerances in terms of appearance and appearance in section.

According to the study of Kasunmala et al. (2020), the absence of gluten in rice flour determines the starch itself to act as the major constituent that provides the cooking tolerance and the mouthfeel sensation during the process of chewing. On the other hand, Ji (2007) assessed the texture of some rice flour cakes and found that the firmness parameter is increasing. They concluded that the absence of gluten would increase the movement of water inside the product towards the crust due to mass transfer, thus resulting in a firmer surface, this being in agreement with the present study where panelists gave a high score to the firmness parameter of the black rice flour biscuits.

The sensory characteristics of the K-332 brown rice flour variety crackers obtained by Mir et al. (2017) displayed a score of 7.51 in terms of appearance, a score of 6.72 for flavor, 7.31 for color, and a score of 7.98 for texture. Meanwhile, for the Khosar brown rice flour variety product, the scores were: appearance 7.26, flavor 6.99, color 7.35, and texture 7.94.

\section{Conclusions}

All the ingredients used to obtain the functional biscuits bring a high intake of protein, fiber, and biologically active compounds thus providing several beneficial 
effects to the human body. The obtained product was analyzed from a physicochemical, microbiological and sensory analysis point of view, and the results being in accordance with the specific Standard methods.

The black rice flour biscuits presented high content of proteins and fibers so that their functionality is mainly being given by the high content of biologically active compounds. The in vitro digestibility studies have shown that the complex matrix of the biscuits permitted the protection of the anthocyanin compounds in the gastric juice, allowing their gradual release in the intestinal juice. The black rice flour biscuits did not have an antigenic potential, thus they can be successfully included in the category of aglutenic products.

The microbiological tests revealed the stability of the product during storage for 21 days with yeasts and molds being absent, making the product safe for consumption throughout this whole period.

\section{Acknowledgments}

This work is supported by the project "ANTREPRENORDOC", in the framework of Human Resources Development Operational Programme 2014-2020, financed from the European Social Fund under the contract number 36355/23.05.2019 HRD OP /380/6/13 - SMIS Code: 123847.

\section{References}

AOAC. 1990. Official Methods of Analysis of the Association of Official Analytical Chemists, Vol. II, 15th ed. Sec.985.29. The Association: Arlington, VA.

ASRO (2008). Romanian standards catalog for cereal and milling products analysis. SR ISO 2171/2002, Bucharest

Ajila, C.M., Prasada Rao, U.J.S., 2008. Protection against hydrogen peroxide induced oxidative damage in rat erythrocytes by Mangifera indica L. Peel extract. Food Chemical Toxicology, 46, 303 -309.

Aleman, R.S., Paz, G., Morris, A., Prinyawiwatkul, W., Moncada, M., King, J.M. 2021. High protein brown rice flour, tapioca starch \& potato starch in the development of gluten-free cupcakes. $L W T, \mathbf{1 5 2}, 112326$.

Bolea, C., Turturică, M., Stănciuc, N., Vizireanu, C. 2016. Thermal degradation kinetics of bioactive compounds from black rice flour (Oryza sativa L.) extracts. Journal of Cereal Science, 71, 160-166.

Cao, H., Saroglu, O., Karadag, A., Diaconeasa, Z., Zoccatelli, G., Conte-Junior, C.A., Gonzalez-Aguilar, G.A., Ou, J., Bai, W., Zamarioli, C.M., Pedro de Freitas, L.A., Shpigelman, A., Campelo, P.H., Capanoglu, E., Hii, C.L., Jafari, S.M., Qi, Y., Liao, P., Wang, M., Zou, L., Bourke, P., Simal-Gandara, J., Xiao, J. 2021. Available technologies on improving the stability of polyphenols in food processing. Food Frontieres, 2, 109-139.

Das, A.B., Bhattacharya, S. 2019. Characterization of the batter and gluten-free cake from extruded red rice flour. LWT. Food Science and Technology, 102, 197-204.

Dillard, C.J., German, J.B. 2000. Phytochemicals: nutraceuticals and human health. Journal of the Science of Food and Agriculture, 80, 1744-1756.

Fang, J. 2014. Bioavailability of anthocyanins. Drug Metabolism Reviews, 46(4), 508-520. 
Gallagher, H. L., Frith, C. D. 2003. Functional imaging of "theory of mind." Trends in Cognitive Sciences, 7, 77 - 83.

Hooda, S., Jood, S. 2005. Organoleptic and nutritional evaluation of wheat biscuits supplemented with untreated and treated fenugreek flour. Food Chemistry, 90, $427-$ 435 .

Indriani, S., Karim, M.S.B.A., Nalinanon, S., Karnjanapratum, S. 2019. Quality characteristics of protein-enriched brown rice flour and cake affected by Bombay locust (Patanga succincta L.) powder fortification. LWT. Food Science and Technology, 119, 108876.

Ji, Y. 2007. Staling of cake prepared from rice flour and sticky rice flour. Food Chemistry, 104, 53-58.

Jnawali, P., Kumar, V., Tanwar, B. 2016. Celiac disease: Overview and considerations for development of gluten-free foods. Food Science and Human Wellness, 5, 169-176.

Kasunmala, I.G.G. Navaratne, S.B., Wickramasinghe, I. 2020. Effect of process modifications and binding materials on textural properties of rice noodles. International Journal of gastronomy and Food Science, 21, e100217.

Kim, I., Moon, J.K., Hur, S.J., Lee, J. 2020. Structural changes in mulberry (Morus Microphylla. Buckl) and chokeberry (Aronia melanocarpa) anthocyanins during simulated in vitro human digestion. Food Chemistry, 318, 126449.

Marnett, L.J. 2000. Oxyradicals and DNA damage. Carcinogenesis, 21, 361-370.

Mir, S.A., Bosco, S.J.D., Shah, M.A., Santhalakshmy, S., Mir, M.M. 2017. Effect of apple pomace on quality characteristics of brown rice based cracker. Journal of the Saudi Society of Agricultural Sciences, 16, 1, 25-32.

Oancea, A.-M., Aprodu, I., Ghinea, O.I., Ioniță, E., Râpeanu, G., Barbu, V., Bahrim, G., Stănciuc, N. 2017. A bottom-up approach for encapsulation of sour cherries anthocyanins by using $b$-lactoglobulin as matrices. Journal of Food Engineering, 210, 83-90.

Sangma, H., Cherik, R., Parameshwari, S. 2021. Health benefits of black rice (Zizania aqatica) - a review. Material stoday: Proceedings.

Segal, R., Barbu, I. 1982. Analiza senzorială a produselor alimentare. Editura Tehnică Bucuresti.

Sidhu, J. S., Suad, N., Al-Saquer, J.M. 1999. Effects of adding wheat bran and germ fractions on the chemical composition of high fiber toast bread. Food Chemistry, 67, $365-371$.

Stevens, J.F., Maier, C.S. 2016. The chemistry of gut microbial metabolism of polyphenols. Phytochemistry Reviews, 15(3), 425-444.

Sudha, M.L., Vetrimani, R., Leelavathi, K. 2007. Influence of fibre from different cereals on the rheological characteristics of wheat flour dough and on biscuit quality. Food Chemistry, 100, 1365- 1370.

Tyagi, S.K., Manikantan, M.R., Harinder, S.O., Gurlen, K. 2007. Effect of mustard flour incorporation on nutritional, textural and organoleptic characteristics of biscuits. Journal of Food Engineering, 80, 1043-1050.

Vitali, D., Vedrina Dragojević, I., Šebeĉić, B. 2008. Bioaccessibility of $\mathrm{Ca}, \mathrm{Mg}, \mathrm{Mn}$ and $\mathrm{Cu}$ from whole grain tea biscuits: Impact of proteins, phytic acid and polyphenols. Food Chemistry, 110, $62-68$.

Wang, S.Y., Jiao, H. 2000. Scavenging capacity of berry crops on superoxide radicals, hydrogen peroxide, hydroxy radicals and singlet oxygen. Journal of Agricultural and Food Chemistry, 48, 5677-5684.

Wesley, S.D., Andre, B.H.M., Clerici, M.T.P.S. 2021. Gluten-free rice \& bean biscuit: characterization of a new food product. Heliyon, 7, e05956. 